\title{
Notas léxicas a las Siete edades de mundo de Pablo de Santa María ${ }^{1}$
}

\author{
Juan Carlos Conde \\ Instituto de Lexicografía \\ Real Academia Española
}

El converso Pablo de Santa María (c1353-1435), una de las personalidades más interesantes de la vida castellana de su tiempo, tanto en lo político como en lo literario? escribió hacia 1418 Las siete edades del mundo. Esta obra es un sumario historiográfico, escrito en verso de arte mayor, que combina un relato de historia universal planeado conforme a las pautas del género vigentes a lo largo de la Edad Media con un relato de historia nacional de indudable vinculación con el modelo historiográfico alfonsí, aunque no exento de una cierta voluntad de originalidad ${ }^{3}$.

La condición de sumario de la obra condiciona, lógicamente, su contextura lingüística. Concentrar en 338 estrofas de arte mayor el relato de la historia del mundo desde la Creación hasta finales del XIV, y el de la de España desde sus primeros pobladores míticos hasta Juan II de Castilla, obliga a un severo ejercicio de síntesis. Las apelaciones a la brevitas, más allá de la mera alusión al conocido tópico, tan utilizado por los historiógrafos del Medievo, son expresión de uno de los rasgos caracterizadores de la obra. Así se expresa nuestro autor en su prólogo:

Entre otras obras que a la vuestra magestad, muy poderoso Prínçipe e lllustrisimo Rey e Señor, ayan seydo presentadas, so breve compendio de escriptura una

${ }^{1}$ Gran parte de la documentación léxica que se aducen en este trabajo proviene de los ficheros de la Real Academia Española y de los CD-ROM de ADMYTE (Archivo Digital de Manuscritos y Textos Españoles). Es un placer expresar aquí mi agradecimiento por su ayuda y sus indicaciones a Steven Dworkin. María Teresa Echenique, José Antonio Pascual y José Ignacio Pérez Pascual.

2 Noticia biográfica fundamental en Serrano (1942). Cantera Burgos (1952) y Krieger (1988).

3 Han visto la luz varias ediciones del texto: OCHOA (1844), FoulChÉ-DelBosC (1915) y SCONZA (1991); juicio sobre esta última en CONDE (1995a). En breve verá la luz la edición crítica de CONDE (en prensa), acompañada de un extenso estudio sobre el texto, su transmisión y sus modelos; es versión corregida de su tesis doctoral, de donde se toman las citas del texto que aparecen en este trabajo (CONDE 1995b). Además de los trabajos mencionados, merece ser destacado de entre los -pocos- dedicados a esta obra en los últimos años DEYERMOND (1985). 
copilaçión, casi reportorio, de algunas estorias a vuestra alteza pensé dirigir. E acatando que como alguno que quiere traer en recordaçión las fazañas e cosas pasadas [..], la tardança o prolexidat de sus palabras por algunas vegadas traya fastidio e enojo en orejas de aquel que por ventura mas largamente dello ha seýdo ynformado [..], aquesta suma copilaré non alongando nin me deteniendo en la narraçión e continuaçión della porque en la manera sobredicha pueda ser avido por enojoso e tardío en mi fablar (ConDE, 1995b, t. II. p. 1).

La puesta en práctica de esos principios se pone de relieve a todo lo largo de la obra, aunque en algunos puntos alcanza dimensiones espectaculares. Así la estrofa 241 , que, siguiendo las pautas establecidas por el tópico de la translatio imperii, tras la mención de Carlomagno en las estrofas 239-240 se ocupa de la línea de los emperadores del Sacro Imperio Germánico de forma particularmente expeditiva: "Ya por abreviar esto continuando / otros [emperadores] dexaré que vinieron después, / los quales por cuenta fueron veinte e tres / fasta el quinto Enrique" (CONDE, 1995b, t. II, p. 254). Por mor de la brevedad, 23 emperadores son despachados de un plumazo.

Por consiguiente, la constante voluntad de brevedad de que hace gala Pablo de Santa María en sus Siete edades del mundo da lugar a la creación de un relato caracterizado por lo sucinto de la descripción de los sucesos y por la práctica ausencia de ornatus o artificio retórico. Este rasgo, asociado a la propia naturaleza historiográfica del texto, da lugar al empleo de un cierto tipo de léxico en la obra, en general desprovisto de toda función que no sea la meramente denotativa, y por completo encaminado a la configuración de la columna vertebral de la línea historial diseñada, sin adiciones moralizadoras, ejemplificantes o en general digresivas.

Tal ajuste entre el plano de la expresión y el plano del contenido -por recuperar cierta terminología escolar ya un tanto añeja- es fácilmente perceptible, y muy fácilmente verificable y cuantificable por medio del empleo de un programa de generación de concordancias y estadísticas léxicas ${ }^{4}$. Las Siete edades contienen unas 3.300 formas o palabras gráficas diferentes, de las cuales unas 2.950 tienen una frecuencia de aparición inferior a cinco, y unas 2.000 aparecen una sola vez en el texto. El análisis de tales frecuencias puede, indudablemente, facilitar un mejor conocimiento de la fisonomía del léxico de la obra. Así, y centrándonos en el caso de los sustantivos, no debe extrañarnos en un relato historiográfico de ámbito universal, en gran medida articulado en torno al tópico de la translatio imperii, que el más repetido sea rey (rey 102 ocurrencias, reyes 21, reina 9; cf. emperador 9, emperadores 11 ), al igual que no debe sorprender que la carga genealógica inherente a un relato historiográfico basado en la

${ }^{4}$ El empleado para la elaboración de los recuentos que aquí se presentan es TACT, versión 2.1, desarrollado por un grupo de expertos de la Universidad de Toronto. Es obtenible gratuitamente a través de Internet. por FTP (file transfer protocol) a la dirección ftp.epas. utoronto.ca/pub/cch/tact/tact2.1. operación ejecutable igualmente a través de la página en el World Wide Web de TACT:

http://www.chass.utoronto.ca/cch/tact.htm. 
transmisión y herencia de la corona real sea responsable de que fijo sea el segundo sustantivo más utilizado (fijo 79 ocurrencias, fijos 21; fija 8, y fijas 2; cf. las 9 ocurrencias de subçessor, las 4 de subçessión y las 5 de heredero). Ese señorío real transmitido de padres a hijos se ejecuta sobre un territorio y a lo largo de un devenir temporal, por lo que no extrañan las 64 ocurrencias de tiempo y las 8 de tiempos, las 58 ocurrencias de tierra o las 49 de reino ( 15 de ellas en plural). Al número de ocurrencias de este último sustantivo superan otros dos, en absoluto sorprendentes en una obra historiográfica de ámbito universal more christiano, como la que tratamos aquí: año (59 ocurrencias), Dios (54) y señor (52).

Por lo que se refiere a los verbos, no debe sorprender en un relato de estas características el predominio absoluto de las formas de pretérito del verbo ser (fue 246 ocurrencias, fueron 107, era 42, fuesse 33, eran 11); estadísticamente, las primeras formas no pretéritas de este verbo son formas no personales: $\operatorname{ser}$ (22 ocurrencias) y seyendo (20). No hay ninguna forma personal del verbo ser de tiempo no pretérito que supere las cinco ocurrencias en el texto.

El siguiente verbo estadísticamente más relevante en las Siete edades es -y no sorprende- el verbo fazer. De nuevo predominan las formas en pretérito: fizo 55 ocurrencias, fiziera y fizieron 8 ocurrencias ( $c f$. el caso de fazer, con 14 ocurrencias). Las cifras, con todo, están significativamente alejadas de las correspondientes al verbo ser; mayores todavía son las que separan a fazer de los demás verbos más utilizados: significativamente reinar (56 ocurrencias) es uno de los que se encuentran encabezando este grupo (reinó 29 ocurrencias; la siguiente forma de reinar es precisamente el infinitivo, con 14 apariciones). El componente genealógico y regio del relato cobra cuerpo en la estadística de subçeder (32 ocurrencias, 18 de ellas correspondientes al pretérito indefinido). En fin, en un relato historiográfico tampoco debe sorprender que los adverbios más utilizados sean adverbios de tiempo: después (206 ocurrencias), luego (87), quando (73).

Esta imagen de previsibilidad del léxico de las Siete edades que se acaba de trazar, objetivando y cuantificando lo obvio, no cierra la puerta, sin embargo, a la aparición de tal o cual vocablo que se escapa de esta tendencia general y que, por una u otra razón, reviste interés para el historiador del léxico. A algunos de estos casos pretendo dedicar unas líneas que, además de ayudar a la adecuada intelección del pasaje de las Siete edades del mundo en que se hallan, puedan ser una mínima aportación a la historia del léxico del español medieval ${ }^{5}$.

5 La razón última de estas escuetas notas es la carencia de un diccionario del español medieval que todavía padecemos. Será un excelente instrumento el Diccionario Histórico de la Lengua Española, que de sobra supliría la deficiencia lexicográfica mencionada, pero su lento ritmo de publicación (dos tomos hasta ahora que no abarcan la totalidad de las palabras comenzadas por $a$. un fascículo del tomo III y otro del IV. con material ya correspondiente a la letra $b$ ) hacen que la laguna siga sin colmar. Otras contribuciones al respecto, como el inefable Vocabulario del español medieval de JuLIO CEJADOR, resultan claramente insuficientes (co- 


\section{-BROCÁRDICO 6}

Acatando que como alguno que quiere traer en recordaçión las fazañas e cosas pasadas o mayormente recontar o dezir algunos otros fechos e cosas nuevas contesçidas, la tardança o prolexidat de sus palabras por algunas vegadas traya fastidio e enojo en orejas de aquel que por ventura mas largamente dello ha seýdo ynformado, así de algunas estorias recoligiendo çiertas cosas que más por manera de brocárdico que por otra escriptura sean avidas, aquesta suma copilaré non alongando nin me deteniendo en la narraçión e continuaçión della porque en la manera sobredicha pueda ser avido por enojoso e tardío en mi fablar (Prólogo, ed. CONDE, 1995b, t. II, p. 1).

Apparatus: brocardico ML*] brocardio SA12 : vrocandico EM12 : bocardico OC1 : brocadio MRE17

Lo que han dicho sobre esta palabra los editores de las Siete edades que se han ocupado de ella no resulta muy esclarecedor. Eugenio de Ochoa edita bocardico, la lectura de su manuscrito base, MN63 (codex descriptus de OC1 elaborado en el s. XVIII) en vez de brocárdico (ОсHOA, 1844, p. 98): ese error cometido a la hora de dar con la forma correcta de la lectio original del texto le dificultó su posterior elucidación. Ochoa anota el pasaje así: "No sé qué es bocardico; pero parece por el sentido que debe significar cosa que pasa de boca en boca, y vendrá a ser lo mismo que tradición oral. Todo este prólogo está incorrecto y confuso por demás" (OCHOA 1844, p. 106). Salta a la vista que Ochoa -y le delata la apostilla- no sabía por donde se andaba, y aventuró una interpretación como buenamente Dios le dio a entender.

mo queda de relieve con hojearlo; vid. el prólogo que acompaña un reciente reprint: CoNDE-INFANTES, 1990); más o menos igual sucede con el más reciente Diccionario medieval español de MARTín Alonso (1986). Beneméritos, pero insuficientes, además de prácticamente inencontrables, son OELSCHLAGËR (1940) y BoGGS. KASTEN. KENISTON, RICHARDSON (1946). Una contribución más rigurosa, como el Diccionario del español medieval dirigido por Bodo Müller, lleva camino de superar la proverbial lentitud de publicación del Diccionario histórico académico. Un adecuado status quaestionis de la lexicografía sobre el español de la Edad Media es DworKIN (1994), review article dedicado a las mencionadas obras de Alonso y Müller. Dworkin es coautor de uno de los trabajos con que más decorosamente puede cubrirse -en parte- la carencia de un diccionario del español medieval a base de la recopilación de la información presente en vocabularios. glosarios y monografías: BILLICK-DWORKIN (1987); ha sido ya objeto de una segunda edición revisada y ampliada: BILLICK-DwORKIN (1993).

6 Un primer acercamiento a la presencia de esta voz en Las siete edades del mundo se halla en CONDE (1995a), p. 329.

7 Las siglas por las que se identifican los diversos mss. de Las siete edades del mundo a lo largo de este trabajo son las establecidas en DutToN (1990-1991); allí se encontrará toda la información precisa sobre cada uno de ellos (vid. el índice de fuentes manuscritas del t. VII, pp. 659-64, para las equivalencias). El caso de ML* es anómalo. pues este ms.. el 425 de la Biblioteca Lázaro Galdiano de Madrid, no fue recogido por Dutton en su repertorio; para la sigla propuesta, vid. CONDE (1995b), pp. 475-78 y CoNDE (en prensa), cap. V.1.1, donde se ofrece descripción codicológica de todos los mss. de las Siete edades. 
Sconza edita brocardio, lectura de su manucrito base, SA12 (SconZA, 1991, p. 53), y también echa su imaginación a volar: "His [sc., de Pablo de Santa María] specific reference to "brocardio" in line 10 (cf. Sp. and Port. brocado, It. broccato, Lat. brocchus) suggests that the poem possesses a certain texture resulting from the weaving together of various accounts". Y añade, acto seguido: "In his commentary on the prose prologue, which accompanies his edition of the poem, Eugenio de Ochoa remarks: "No sé qué es 'bocardico'; pero parece por el sentido que debe significar 'cosa que pasa de boca en boca', y vendrá a ser lo mismo que 'tradición oral'". His inability to understand the prologue led him to conclude: "Todo este prólogo está incorrecto y confuso por demás" (SCONZA, 1991, p. 175).

Es cierto que la nota al pasaje de Ochoa no es satisfactoria, pero la de Sconza, casi 150 años posterior, resulta incluso peor. Su explicación surge, como la de Ochoa, de la incapacidad para dar con la lectio correcta escrita por Pablo de Santa María. Ni bocardico ni brocardio son formas documentadas, hasta donde yo sé, en español, por lo que es preciso editar la lectio transmitida por $\mathrm{ML}^{*}-\mathrm{ms}$. del XVI, a diferencia de los otros mencionados, todos del XV-: brocárdico, voz que existe en español ${ }^{8}$ ( $<$ lat. med. BRoCARDICUM, cf. fr. brocard, < lat. med. BROCARDUM) ${ }^{9}$, y que REAL ACADEMIA ESPAÑOLA (1992), define: "desus. Entre los profesores de derecho, sentencia, axioma legal o refrán". Está ya en el Diccionario de Autoridades (Real AcADEmia Española, 1726-39, s.v.), definida como 'sentencia, axioma o aphorismo trivial y sabido de todos, que algunos estudian para vana ostentación', y autorizada por un texto de Saavedra Fajardo, República lite-

8 Es forma cuyo malentendimiento por parte de los copistas verosímilmente genera las lectiones de los diferentes mss. de las Siete edades que se han consignado supra.

9 Para el término latino, vid. Du CANGE (1840-1850), s.v. brocardicum 'iuris axioma: gall. [por gallus] brocard, hispan. brocardico', aduce documentación latina del s. XIII. También recoge las formas brocardum. brocarda y bocartica, todas con el mismo significado. Vid. también NIERMEYER (1984), s.v. brocardum 'adage de droit': la no presencia del término en el Thesaurus linguaE latinae (1900- ), en el OXford Latin Dictionary (1986) o en GAFFIOT (1934) muestra la génesis medieval del término. Conste aquí que la voz no aparece en Palencia (1490) ni en NebriJA (1492). Por lo que respecta al francés brocard, vid. LiTTRÉ (1863-1896), s.v., 'terme d'ancien droit. Nom des principes ou premières maximes du droit'. A esta acepción, acorde con los valores del lat. brocard(ic)um, añade Littré otra: 'paroles mordantes, trait piquant'. En cuanto a la etimología, Littré refleja la procedencia del "bas-latin BROCARDA, BROCARDICUM, BROCARDICORUM OPUS", y explica la teoría comúnmente más aceptada: “..qui signifiant sentences de droit contenues dans un ouvrage qui compila, dans le XIe siècle. Burchard, évêque de Worms". La ampliación al significado de la segunda acepción se explica, según Littré: "Burchard ou Brocard donna son nom au livre, burcardus, aux sentences brocardiques; et les sentences mêmes ont donné, par extension et plaisanterie, le leur aux brocards, paroles moqueuses". Para una opinión opuesta respecto del asunto de la etimología y la derivación del fr. brocard -en su opinión, la voz latina procedería de la francesa-, vid. SPITZER (1955). Vid. también para el fr. brocard -no recogido en Godefroy (1880)-, el TRĖSOR DE LA LANGUE FrançAISE (1971-1994), s.v., donde solo aparece la acepción de uso actual, 'railleries écrits ou orales souvent mordantes', pero se aducen interesantes datos en los apartados "étymologie" e "histoire". Al hilo de la etimología propuesta para el brocárdico español, hago constar aquí que no figura en COROMINAS - PASCUAL (1980-1991). 
raria ${ }^{10}$. No consta en NebriJa (1495) ni en CovarRubias (1943). Es posible encontrar documentación anterior al texto de Saavedra Fajardo: en el siglo XV brocardico -con acentuación llana, según el editor del texto- aparece en la Crónica de Álvaro de Luna: "bien es verdadero aquel brocardico que se suele dezir: con quien pasçes, que non con quien nasçes" (1940, p. 280, 17); "E se cunplió bien en él aquel brocardico que se suele dezir: "Quien con mal anda, con mal acaba»" (ibid., p. 352, 16); "aquel vulgar brocardico que dize: "Una cosa piensa el bayo, e otra el que le ensilla»" (ibid., p. 417, 18). Ahí prevalece el significado 'refrán, frase proverbial, dicho popular' -cercano al segundo de los recogidos por los diccionarios franceses ('mot piquant')- ya señalado por ElEANOR S. O’Kane (1950). En cambio, el significado de la voz en el texto de Pablo de Santa María se halla más cercano al recogido por los diccionarios académicos y al consignado para el lat. brocardicum y el fr. brocard por los diccionarios de esas lenguas: 'compilación de máximas o formulaciones escuetas', y gira en torno a la idea de 'compendio' que el autor repetidamente presenta en su prólogo como rasgo caracterizador de las Siete edades; tal relación resulta igualmente pertinente desde el punto de vista de la autoridad didáctica intrínseca a la sentencia, ya que Las siete edades del mundo fueron escritas por Pablo de Santa María en su período de preceptor del rey niño Juan II, por lo que brevedad y sentenciosidad, conceptos hermanados en la voz que venimos comentando, se erigen como criterios informadores de la construcción del texto. Con todo, puede sorprender a primera vista la utilización de la voz por Pablo de Santa María, dada su escasísima difusión en español y el carácter de tecnicismo jurídico que arrastra desde sus orígenes. No es, sin embargo, tan extraño, ya que la voz nos remite a los ambientes universitarios jurídicos parisinos, donde lat. brocardus o brocardicus vale 'dicho compendioso, máxima legal o compilación de tales dichos o máximas' -a través de complicados vericuetos semánticos escudriñados por SPITZER (1955)-, y no conviene olvidar el paso de Pablo de Santa María por las aulas parisinas, lo que sin duda puede explicar su familiaridad con el concepto ${ }^{11}$.

Es interesante anotar que, aproximadamente por las fechas en que Pablo de Santa María escribía su obra, podría documentarse otra voz emparentada con brocárdico: se trata de bocardo (< B(R)OCARDUM), presente en una respuesta de Fray Lope del Monte a una composición de Diego Martínez de Medina, conservadas ambas únicamente en el Cancionero de Baena. Y se ha hecho uso del condicional porque el texto presenta dificultades de lectura y de entendimiento. El texto dice: "Notilo [sic] afirmó Bernardo /

10 "Algunos mui aprisa se paseavan, encomendando a la memoria aforismos i brocárdicos para parezer doctos" (SAAVEDRA FAJARDO, 1973, p. 79). Es de notar que la connotación negativa del contexto en el que Saavedra utiliza la voz -se trata del pasaje en el que se visita "la casa de los locos" (ibid., p. 77) de la república literaria- deja huella en la definición de Autoridades, connotación sin fundamento en la historia de la voz, tanto en latín como en francés y español. Nótese asímismo que el artículo brocárdico está incorrectamente alfabetizado en Autoridades, pues aparece entre brocadura y brocal (REAL ACADEMIA ESPAÑOLA, 1726-1739, t. I, p. 686a).

11 Documenta este extremo de la peripecia vital de nuestro autor SerRano (1942), pp. 26-30. 
con reguardo / estable e determinado, / en le ferir con tal dardo / como sardo / a la Virgen tan osado; / su dicho non faz' alardo / sin descardo / lo que diré afincado, / pues argüid por Bocardo, / que ya ardo / veyendo mal silogicado" (CANCIONERO DE BAENA, 1993, p. 581). Los responsables de esta edición, Dutton y González Cuenca, indican la dificultad altísima que ofrece el poema, y en lo que nos afecta anotan: "Bocardo podría ser Burcardo, Obispo de Worms (h. 965-1025), autor de un Decretum (h. 1010), precursor de la Concordancia de Graciano" (ibid.); consecuencia de lo ahí dicho es la decisión de editar bocardo como nombre propio, con mayúscula inicial. La misma consideración aparece en DutTon (1990-1991, t. VII, p. 77, n 1454), pese a que los criterios paleográficos de edición del texto lleven a imprimir bocardo con minúscula inicial (ibid, t. III, p. 225b). La lectura de bocardo no admite dudas en el ms. (CANCIONERO DE BAENA, 1926, fol. $116 v^{\circ}$ a); sí que las encierra la interpretación del pasaje. Opino que mejor que el nombre propio del jurista germánico cuadra mejor entender aquí bocardo como resultado del lat. B(R)OCARDUM, lo que permite dar mejor cabida al valor instrumental del por que le precede, perfectamente coherente ('argüír por medio de sentencias o principios'). Es la opinión recogida en el primer Diccionario histórico de la Academia (REAL ACADEMIA ESPAÑOLA, 1933-1936, s.v.): 'término mnemotécnico usado por los lógicos para designar uno de los modos legítimos de la tercera figura del silogismo' definición que se aplica al texto de Fray Lope del Monte y que se toma de TerReros (1786-93, s.v. bocardo), que también se cita ahí. SCHMIDT se limita a transcribir la definición del Diccionario histórico (1951, p. 36). En tal caso -y, en realidad, también si se sostiene la interpretación aventurada por Dutton y González Cuenca-, parece que bocardo ha de ser error de transmisión por el esperable brocardo; el hecho de que el poema se conserve únicamente en el de Baena y no en otros cancioneros hace incomprobable esta conjetura. Si es cierta, nos hallaríamos ante un testimonio complementario -y más o menos coetáneodel que comentamos de las Siete edades, descendiente uno de BROCARDICUM y otro de BROCARDUM (o, más verosímilmente, del fr. brocard), ambos con un mismo significado ${ }^{12}$.

A la vista de los datos aducidos, la aparición de brocárdico en las Siete edades representa la primera documentación conocida de la voz en castellano, anterior en unos cincuenta años a la de la Crónica de Álvaro de Luna -donde la voz, no se olvide, posee otro significado- y en casi dos siglos a la de Saavedra Fajardo ${ }^{13}$.

12 Conozco otra documentación de bocardo, pero sus peculiares características no permiten decir mucho acerca de su significado, pues consta en unos Disparates de Pedro Manuel Jiménez de Urrea (a1536): “Vino allí Pero Gallardo / Con su oficio placentero, / Rinyendo con un portero / En la manga de un tabardo, / Abrazado con un dardo, / Regañando el ojo izquierdo, / Diciendo: lo que yo pierdo / Ganan fapesmo y bocardo; / Y fuese en un asno sardo" (JimÉnEZ DE URREA, 1878, p. 169).

13 Otro ejemplo de la difusión de la voz en la Península es el brocart que aparece en dos pasajes del Espill del valenciano Jaume Roig; vid. COROMINES, que dice que su significado "més aviat sembla ser idèntic a brocard 'axioma o sentència legal' mot bastant conegut en francès" (1980-1991), t. II. p. 249b. Uno de estos dos textos del Espill (v. 8041) se cita en Alcover-Moll (1964), s.v. brocart, con definición dubitante ('excessivament adornat?') y calificación gramatical de adjetivo. 


\title{
-COMPAGO / VIRAGO
}

\author{
Después que la muger así fue formada \\ de aquella costilla que Dios le tomó, \\ delante de Adán el Señor la llamó \\ por ver cómo quería que fuese llamada; \\ e dixo: "Porqu'es de mis huessos sacada \\ e de la mi carne fecha tal compago. \\ por ende su nombre será ya virago. \\ porque de varón ella fue tomada" (ed. CoNDE, 1995b, p. 19, estrofa 9)
}

Apparatus: fecha] fecho OC1 BC4 // compago] propago $\psi$ [=BC4 BM3 16CB]: en pago MN39 : persona MN42 : carona MRE1.- 7. por ende om. BC4 // su nombre será ya virago] su nombre sera ya varona $\delta[=\mathrm{MN} 42 \mathrm{MRE1}]$ : su nombre sea ya virago MN39 : sea su nonbre lamado virago BC4 : su nombre se llame virago BM3.-

Nos encontramos en los comienzos de la obra, en la parte en que el texto de las Siete edades sigue muy de cerca el texto del Génesis. Esta estrofa se corresponde con Gen 2,22-23: "Et aedificavit Dominus Deus costam, quam tulerat de Adam, in mulierem: et adduxit eam ad Adam. Dixitque Adam: Hoc nunc, os ex ossibus meis, et caro de carne mea: haec vocabitur Virago, quoniam de viro sumpta est". Revisemos por separado los casos de compago y virago, aunque su aparición en el texto se explica desde similares presupuestos.

Hasta donde sé, compago es voz muy escasamente documentada en español, y con significados muy diversos. Así, y además del texto de las Siete edades, se halla en Diego Ufano, Tratado de la artillería: “La segunda destas pieças [de artillería] paresçe tiene mejor garbo y forma [..]. Pero la terçera es de forma y talle tan ynútil que ni con ella se podrá(r) quitar deffensa ni batir muralla [..]. A ella le llamaron compago, no sé porqué, que mejor le quadraua codauo" (UFANo, 1613, p. 12) ${ }^{14}$, y en el diccionario académico de 1780, donde se registra la acepción 'lo mismo que compás por atrio o lonja en las iglesias' (REAL ACADEMIa ESPAÑola, 1780, s.v.), del todo ajena a los textos mencionados. Es obvio que el texto de Ufano y la definición del diccionario académico no ayudan a entender el texto de las Siete edades. También se documenta en español la voz compage: el Diccionario de Autoridades (primera documentación de la palabra según CoroMINAS-PASCUAL, 1980-1991, s.v. página) la define como 'Ayuntamiento, enlace, juntura o conjunción y trabazón de una cosa con otra. Es voz puramente latina' (REAL ACADEMIA

14 Describe una pieza de artillería cuyo cañón, en vez de tener forma rectilínea, presenta una curiosa disposición angular, en forma de codo (de ahí la propuesta alternativa de Ufano). A la vista de los diccionarios latinos que enseguida se aducirán. es evidente que la pieza recibe ese nombre -se le escapa a Ufano- por no estar formada de una sola pieza, sino de dos estrechamente unidas por medio de una soldadura en forma de ángulo. 
ESPAÑOLA, 1726-1739, s.v.). Hay documentación anterior a la proporcionada por Corominas-Pascual, así 1617-37, Quevedo, Política de Dios: "Los pasos quebrados, el cuerpo disoluto, desencuadernada la compage de los miembros" (Quevedo, 1932, p. 371); poco posterior a la documentación de la voz en Autoridades es la ofrecida por Torres Villarroel en 1736 en Los desahuciados del mundo y de la gloria, parte de sus Sueños morales: "La turbación y la cobardía alteran, precipitan y desfiguran el natural texido y el ordenado movimiento de la sangre, y la dexa débil [..]. Quando goza este hermoso líquido sosegada circulación, feliz compage y natural textura, arroja valerosamente las partes extrañas" (ToRRES VillarRoel, 1794, p. 8). No he podido encontrar más documentación. Otra voz relacionada con compago es compagamiento ("lo mismo que compage", REAl ACADEMIa ESPAÑOLA, 1780, s.v.), documentada a fines del XV: "E de aqui viene que caen las hojas de los arboles [..] avnque en algunos queden, asi como es en el buxo e laurel [..] o por la susficiencia del su humor [..] o por el compagamiento e fortaleza del madero" (BuRGos, 1494, fol. aajd $)^{15}$, donde el sentido es el mismo de 'trabazón, contextura, juntura'.

Un vistazo a los diccionarios latinos ayuda a explicar compago (y el mencionado compage). El Thesaurus Linguae Latinae registra compages, -is y compago, -inis con acepciones prácticamente idénticas ${ }^{16}$. La primera (I) en ambos artículos vale 'compactio, colligatio, compositio', dividida a su vez en dos subacepciones: (I.A) 'status eius quod compactum est' (en el caso de compages también 'actio compingendi') y (I.B) 'res ex diversis partibus compacta'; esta dicha tanto 'de rebus corporeis' (I.B.1) como 'de rebus incorporeis' (I.B.2). La segunda acepción en ambos artículos vale 'commissura, iunctura', y la tercera, 'id quod continet, vinculum': estas dos últimas no nos van a interesar demasiado aquí. Tanto en el caso de compages como en el de compago, la acepción I.B.1 presenta una copiosísisma documentación en la que con frecuencia se halla la secuencia "compages corporis", "compago corporis"; es de notar que, conforme a lo afirmado en el mencionado estudio acerca de la utilización de ambas formas que abre el artículo compages, la mayor parte de la documentación aducida s.v. compago procede de autores latinos de la baja latinidad y la alta edad media (Pelagio, Jerónimo, Isidoro, Prudencio). A esto se añade compagus, $-i$, 'fortasse i. q. compaganus' definido este último como 'eiusdem pagi incola' y escasamente documentado. Otros diccionarios latinos confirman esta visión ${ }^{17}$.

15 Se trata, como es sabido, de una traducción del De proprietatibus rerum de Bartholomaeus Anglicus.

16 En el artículo compages -is se ofrece un detallado estudio de la alternancia de las dos formas, con examen de las opiniones al respecto de diversos gramáticos y preceptistas latinos. El balance final establece que "praeferunt antiquiores vocem -es; apud recentiores passim legitur nominativus sing. compago, at in casibus obliquis formae a -es ductae praeferuntur".

17 Así OXford LATIN DictionaRY (1986), s.v. compages y compago; en este último, bajo la segunda acepción general de unidad o estructura hay una expresamente referida al cuerpo humano, con ejemplos de Cor- 
A la vista de este panorama y del contexto en que se halla la voz, es sencillo entender el compago de nuestro texto como descendiente directo del lat. compaGo con el sentido 'trabazón de miembros, organismo con cierta estructura y composición', con fundamento en el concepto expresado en Gén 2, 23, fuente directa del texto18. Lo que resulta más difícilmente explicable es la razón por la que Pablo de Santa María decidió emplear término tan inusitado. Lo inmediato es pensar en las exigencias de la rima: no es sencillo encontrar voces encajables a este respecto con virago. Pero esa razón se desvanece de inmediato: bastaba con no ubicar virago en posición de rima para evitar el problema ("por ende virago será ya su nombre" hubiera sido una posibilidad obvia, con rima tan fácil -y hasta trivial, en ese contexto- como hombre). No creo tampoco que nos hallemos ante una de esas ostentaciones de habilidad versificatoria a que tan dados eran los poetas cancioneriles, que, especialmente en juegos de preguntas y respuestas, que exigían respuesta por los mismos consonantes, planteaban a sus adversarios verdaderos tours de force por medio de la utilización de palabras extrañas -en lo que respecta a su fonomorfología- en posición de rima: salvar decorosamente el reto daba timbre de excelencia versificadora. Un vistazo al conjunto de Las siete edades del mundo niega de inmediato esta posibilidad.

Hay una explicación para el uso de compago, desde luego, que tiene que ver con la fuente de las Siete edades del mundo en este pasaje. La voz compago (ni compages) no aparece en la Vulgata ${ }^{19}$, es cierto, ni tan siquiera en la Glossa Ordinaria, pero es el mun-

nelio Celso ("compagine corporis") y Quintiliano, Declinationes ("corporum animorumque compago"). Se registra ahí también compagus, - $i$ 'a fellow member of a pagus (as cult-title'). GAFFIOT (1934) registra compages, -is con el sentido genérico de 'assemblage, jointure, construction formée d'un assemblage de pièces', bajo ella se recogen ejemplos interesantes: "compagibus corporis" en Cicerón, De senectute; "compages humana" en Lucano. El sentido de 'articulation' se documenta en Plinio. Compago, -inis aparece con los valores expresados en compages, documentado en Séneca y Ovidio; además aparece compagus como 'village rattaché à un autre". Compages, compago y compagus faltan en NIERMEYER (1984), donde sí se recoge compagensis con el sentido de 'perteneciente al mismo pagus'. Du CANGE (1840-1850) presenta un panorama un tanto disímil. Registra compages, para cuya definición remite a compagus, definido como 'eiusdem pagi'; compago se recoge pero no se define: solo se citan dos textos de veste médica en los que la voz tiene el significado de 'artículación de los miembros'. Debe consignarse la presencia de la voz en PALENCIA (1490), s.v. y en NeBRIJA (1492), s.v.; también aparecen compago y compages como voz interna en NEBRIJA (1495), s.v. travazon.

18 No creo preciso demostrar demasiada atención a una posible hipótesis alternativa, con apoyo en la información aportada por el THeSAURUS LinGUAE LATINAE (1900- ) y Du CANGE (1840-1850), s.v. compagus. $-i$. ya citada arriba. Considerando que Adán y Eva fueron los dos únicos habitantes del Paraíso, este significado de 'eiusdem pagi incola' encajaría en nuestro contexto. En su contra juegan el carácter hipotético ("fortasse..") que tiene en latín, según consigna el THESAURUS LINGUAE LATINAE, la falta de otros derivados en español y, sobre todo, la falta de base en el pasaje bíblico subyacente para esa interpretación. A su favor únicamente tendría la más fácil derivación de la forma castellana, desde el punto de vista de la fonética histórica. a partir de un COMPAGu(M) que de un COMPAGE(M) o un COMPAGINE(M). No parece que esto sea relevante en voces de transmisión exclusivamente culta o libresca.

19 Me refiero al pasaje que venimos comentando. Gén 2, 23. pues en otros lugares sí aparece, aunque con significado diferente del que aquí nos interesa: Éx 26, 24, Dan 5, 6 y Hb 4, 12 son ejemplo de ello. En el primero compago tiene el valor de 'unión, conjunción', y en los otros el de 'articulación (de un miembro del cuerpo)'. Esos pasajes bíblicos son la causa de que compago aparezca registrado en FERNÁNDEZ dE SANTAELLA (1499), f. 40r, s.v. 
do de la exégesis bíblica el que nos da la clave. "Aedificavit Dominus Deus costam [..] in mulierem", lee la letra del Génesis. Y Pablo de Santa María, él mismo exegeta bíblico y autor de unas Additiones a las Postillae con las que el franciscano Nicolás de Lira glosó el sensus litteralis de la Escritura20, hizo cumplida referencia a la relevancia de ese "aedificavit" aplicado a la creación de la mujer. En el Génesis hay tres modos de denominar la "productio hominis": "per hoc verbum formauit, sicut cum dicitur Gen .jj.b: formauit deus homine de limo terrae. Alio modo per hoc verbum genuit, sicut cum dicitur Gen.iiij.d . quod adam genuit seth. Alio modo per hoc verbum edificauit", con alusión a nuestro pasaje de la creación de Eva. A partir de ahí se glosa la primera como "transmutatio", la segunda como "generatio naturalis" y la tercera como "edificatio", con comparación expresa del proceso desarrollado a partir de la costilla de Adán con la de una casa "ex ligno et lapidibus". Por ello "istum modum productionis dicitur edificare, non formare seu generare" (SANTA MARIA, 1502, fol. $39{ }^{\circ} a-b$ ). Es perceptible que a esta interpretación de la creación de Eva subyace la idea de constructo, de estructura orgánica manufacturada, si cabe, en oposición a la creación ex nihilo, y tal idea resulta perfectamente expresada por compago, en su sentido de 'res -en este caso corpus- ex diversis partibus compacta'. Sin duda lo selectivo de las additiones formuladas por Pablo de Santa María a las apostillas del de Lyra -estas sí oceánicas- denota que los puntos objeto de additio eran de especial importancia bajo su punto de vista, y es legítimo pensar que deseó dar cabida en sus Siete edades a todo el trasfondo doctrinal presente en la que acabamos de glosar. El esfuerzo de síntesis exigido por un texto de las características de las Siete edades lo llevó a buscar en el latín el término capaz de tan extremo compendio: tal es la razón última del empleo de compago -latinismo crudo, por lo tanto- en Las siete edades del mundo.

Por lo que respecta a virago, el texto bíblico subyacente explica la presencia de la palabra en las Siete edades, obviamente del lat. VIRAGO -INIS, cf. COROMINAS-PASCUAL (1980-1991), s.v. viril. La primera documentación aducida por este diccionario ${ }^{21}$ es de Juan de Mena, Iliada en romance: "e ya lidiava el belipotente Mares con la casta Palas, movido el egideo escudo, el qual la minérvica e santa virago hiziera" (GonZÁlez Rolán Del BarRio VeGa, 1989, p. 183)22. Pero aquí virago tiene el significado de 'mujer robusta o varonil, guerrera' claramente diferente del que tiene en las Siete edades; refleja un matiz de "mujer de fuerza y arrojo comparables a los del hombre"23, mientras que en nuestra obra -vale decir, y con más propiedad, en Gén 2,23- hay un matiz de proce-

20 Para esta faceta de Santa María, vid. SerRano (1942), pp. 110-113, y las indicaciones bibliográficas aducidas en CONDE (1995b), p. 115.

21 Tomada de SMITH (1959), s.v. viril.

22 La llias latina, base del texto de Mena, lee: "quem sancta virago egit" ((ibid., p. 184). Un vistazo al aparato crítico (ibid., p. 218 y 226) nos permite advertir que en este pasaje las tradiciones manuscritas de los textos castellano y latino no presentan variantes.

23 Es el habitualmente recogido por los diccionarios latinos: cf. Du CANGE (1840-1850), GAFFIOT (1934) y OXfoRd LATIN DictionaRY (1986), todos ellos s.v. virago. 
dencia o genealógico: "virago, quoniam de viro sumpta est". Tal matiz, igualmente a la zaga del texto bíblico, aparece en la primera documentación (c1375) de la palabra que he hallado, en el Libro de miseria de omne: "Adam le dixo virago ante que oviés pecado, / e después la llamó Eva, quando traspasó mandado" (Connoly, 1987, p. 126). La fuente latina de esta obra, el De Miseria conditionis humanae, lee también virago ${ }^{24}$. Otro texto donde hallamos documentado virago muestra igualmente deuda de la letra del Génesis; se trata del Valerio de las estorias escolásticas y de España de Diego Rodríguez de Almela: "El ayuntamiento de omne $z$ muger fue por dios instituydo enel parayso terrenal $z$ el amor fue declarado por angel a adam por gracia de spiritu sancto por aquellas palabras que dixo quando vio a eua. esta es virago por que salio de varon" (RodRiGUEZ DE ALMELA, 1487, fol. 71r). Ese matiz genealógico subyacente, como es lógico, también aparece en los romanceamientos bíblicos medievales, y es causa de la aparición en ellos de varona, calco -sensu lato- de virago más allegado al léxico patrimonial del castellano: frente a una derivación vir > virago encontramos varón > varona. Así en la Biblia Escurialense I.i.3 (de c1400): "e esta será llamada varona, pues de varón fue tomada"; en la Escurialense I.i.4 (igualmente c1400): "aesta lla[ma]ran varona, que de varon fue toma[da] esta (corchetes del ed.)"; y en la Biblia de Alba (¿c1422-33?): "esta varona deue sser llamada, pues de varon fue tomada"25. Ese mismo proceso es detectable en fechas muy anteriores en otro texto donde la impronta de la letra del Génesis y la exegesis medieval es muy fuerte, la General Estoria, que lee "et esta sera llamada uaronessa o varonil por que fue tomada del varon" ("varoessa ou varuyl", según la versión gallega de la General Estoria) ${ }^{26}$. Es perceptible que los redactores alfonsíes también buscaron, bien que con cierta inseguridad, forjar un equivalente romance de virago.

Y la alternancia entre las soluciones virago / varona, varonessa, varonil no solo viene dada por la voluntad de rehuir un latinismo crudo en beneficio de un término menos ajeno a las características del castellano, sino que tiene un trasfondo rastreable en el mundo de la exégesis bíblica, como vimos en el caso de compago. Ya la Glossa interlinearis señalaba que virago como nombre aplicado a la mujer reflejaba la noción de su descendencia - 0 , mejor, procedencia- del varón, tal y como lo hacían los términos hebreos is "hombre, varón" e 'issáh, su femenino, más varona que mujer. Pero exegetas hubo que expresaron su discrepancia de la traducción de san Jerónimo, y llamaron la atención acerca de lo poco afortunado de la elección de la voz latina virago para establecer tal paralelismo: así, Nicolás de Lira, que en sus Postillae indicó: "Ista est locutio impropria: quia virago non signat mulierem de viro sumptam, vel derivatam, sed magis mulierem viriliter agentem [..]. Ista autem deriuatio magis apparet in hebreo vbi dicitur

24 Vid. TESAURO (1985), p. 9. Ahí se etiqueta virago como "latinismo integrado": la impronta de Gén 2. 23 es evidente.

25 Castro-Millares Carlo-Battistessa (1927), p. 3b; Hauptmann (1953), p. 57; y Paz y Melia-Paz (1920-1922), t. I. p. 41 a.

26 Alfonso X (1930), p. $6 a$ y MARTínez-LÓPEZ (1963), pp. 7, 17. 
issa, id est mulier, quod nomen deriuatur ab is, quod signat virum" (LIRA, 1502, fol. $39 r b)$. Semejante postura queda reflejada también en el Vocabularium de Santaella, s.v. virago, donde tras la equivalencia 'varonil' se añade: "conuiene ala hembra quando tiene fuerça $z$ coraçon con obras de varon. fue nombre apropriado a eua porque fue tomada de varon. Algunos dizen que mas proprio traduxera s. hieronimo genesis .ij. vira si en latin se hallase que quiere dezir de varon que virago que significa varonil o en fuerça como varon" (FernándeZ de SANTAELla, 1499, fol. 188r) ${ }^{27}$. Es obvio que Pablo de Santa María opta por el máximo apego al término latino de la Vulgata -especialmente capacitado como estaba, dada su condición de ex rabino, para apreciar lo adecuado de la correlación establecida entre los términos latino y hebreo mencionados- para no tener que optar por soluciones innovadoras o arriesgadas, y emplea virago con los valores presentes en el texto bíblico. Sin embargo, es significativo que dos de los manuscritos de Las siete edades, en concreto los descendientes de uno de los subarquetipos de la tradición textual de la obra, d (MRE1 [s. XV], MN42 [s. XVI]), leen varona28: indicio de que el término virago seguía suscitando insatisfacción en ese contexto.

\section{-LINDOS CRISTIANOS / ÁNGLICAS}

Del fijo menor de aquestos tres hermanos nasçieron Gomer e Magog e Tubal, sin otros fijos que non cuento, del qual desçendieron todos los lindos christianos. así como fueron griegos e romanos e otros de muchas provinçias çercanas, ispánicas, ánglicas e galicanas, con todos los otros reinos comarcanos (ed. ConDE, 1995b, p. 60, estrofa 50).

El uso del adjetivo lindo en este contexto puede resultar chocante a primera vista. Antes que con la belleza, los "lindos cristianos" de este verso tienen que ver con el "cristiano lindo" de un poema de Antón de Montoro ("A un cavallero que le mando vn puerco y no se le dio, diziendo que aun apenas hera christiano"):

Muy más bordado de fee que non de fojas de guindo:

27 El sufijo -ago y su evocación de agere era lo que resultaba más perturbador a la hora de aceptar virago, tal y como denota el "viriliter agentem" de Lira y el alterativo vira, despojado de dicho sufijo, propuesto por Santaella.

${ }^{28}$ La rima se restituye en MN42 con persona, y en MRE1 con carona. Esta última lectura evoca igualmente el texto de Gén 2. 23: "Hoc nunc, os ex ossibus meis, et caro de carne mea". 
¿no saueís cómo gané
carta de cristiano lindo?
Y vos, señor ynportuno
y en las mandas muy prolixo,
mandadme luego dar vno
de los qu'el Rauí maldixo.

Se trata del poema 82 de la edición del Cancionero de Montoro hecha por Francisco Cantera Burgos y Carlos Carrete Parrondo (MonToro, 1984, p. 211): allí, según dicen los editores en nota, vale tanto como 'cristiano viejo' (no 'cristiano nuevo' como interpretó Cotarelo en su edición; MonTORO, 1900, p. ix, nota 3). Las recientes ediciones de la poesía de Montoro llevadas a cabo por Marcella Ciceri-Julio Rodríguez Puértolas (MonTORO, 1990a, p. 74) y Marithelma Costa (MonTORO, 1990b, p. 166) no anotan cristiano lindo. La información contenida en CoROMInAS-PASCUAL (1980-1991, s.v.), aclara el panorama. Lindo (< *lidmo <LEGITIMUS) tiene en sus orígenes el significado de su étimo latino, 'legal, legítimo', como se atestigua cumplidamente desde el siglo XIII: remito a Corominas-Pascual para la documentación; de entre los que ahí se aducen valga como ejemplo la siguiente cita de la Primera Crónica General alfonsí: "heredera linda quel devié aver por natura e por derecho" (Alfonso X, 1906, P. 714a); es fácil acrecer el número de ejemplos, incluso en la misma Primera Crónica General: "Et el rey Eurigo de quien a ya contado la estoria ante desto, ouiera dos fijos: el uno lindo, et este fue ell rey Alarigo del que agora dixiemos, et otro de ganancia a que dixieron Gisalaygo"; en alguna ocasión en uso adverbial: "de estonces, de alli adelante, fue este rrey don Fernando en vno llamado ygualmientre: «rey de Castiella et de Leon», los dos rregnos que el eredo lindamiente de padre et de madre" (ALFonso X, 1906, pp. 247b y 723b, respectivamente). Corominas-Pascual dicen que esta es una "ac[epción] jurídica, y como tal arcaizante, que vivió largo tiempo, pero ya estaba olvidada a fines de la Edad Media", y registran seguidamente otra acepción: "en los SS. XIV y XV es más corriente que [lindo] signifique, por una leve traslación de sentido, 'auténtico', 'puro', a veces 'noble'”. Precisamente la primera documentación aducida por ellos para esta acepción, perteneciente al Fuero Juzgo, es "cristianos lindos"29, y para el significado son muy esclarecedores los siguiente textos de don Juan Manuel, Libro de los Estados: "buenas amas que sean de la mejor sangre et mas alta et mas linda que pudiere haber" y del Cancionero de Baena: "Este es lindo sin toda manzilla, / fijo e nieto de reyes notables" (Villasandino, Dezir a Fernando de Antequera); "delante el muy lindo león sin manzilla" [=Juan II] (Ferrand Manuel de Lando)30; buen complemento a la documentación ofrecida por Corominas-Pascual es el testimonio que consta en un documento de 1485 (AHN, Inquisición

29 Al no aparecer en Corominas-Pascual ninguna indicación acerca de la localización del texto mencionado en el Fuero Juzgo no he podido compulsar la referencia.

30 Manuel (1982), p. 322, 71: Cancionero de Baena (1993), pp. 15 y 640. 
de Toledo, leg. 163, $n^{\circ}$ 525): "cristiana linda" ('cristiana vieja, sin tacha') (SeRRano Y Sanz, 1902, p. 285). En los Siglos de Oro, lindo cobra, según señalan Corominas-Pascual, "un sentido vago de elogio en término generales, tan vasto y comprensivo como el de la palabra bueno". Es evidente que tanto en los casos de Montoro y Pablo de Santa María, y pese al muy distinto tono de sus respectivos textos, la acepción que prevalece es la de 'puro, auténtico, noble'. Mientras que en el caso del cordobés es la limpieza de sangre, la condición de cristiano viejo, la que subyace al texto ${ }^{31}$, en el caso del burgense, y dada la ubicación temporal de la narración -recordémoslo, la descendencia de Túbal-, nos hallamos ante un encomio vago, genérico, más bien orientado a la idea de nobleza, de dignidad especial y superior de los cristianos en contraste con otros pueblos y religiones.

En cuanto a ánglicas, la documentación del adjetivo ánglico en Las siete edades merece un breve comentario porque es, según los datos del Diccionario Histórico de la Lengua Española, s.v. ánglico, la primera conocida -y con mucho- de esta palabra: la siguiente documentación es de 1604 (Lope de Vega Rimas, ed. 1604, fol. 12v) ${ }^{32}$. Otro ejemplo de uso de la voz en el siglo XV -este no recogido en el Diccionario Históricoconsta en el Invencionario de Alfonso de Toledo (c1467): "Anselmo fue de naçion anglico e arçobispo cantuariense" (TolEDo, 1992, p. 202).

\section{-ESPAÑONES}

D'aquestos siete sobre dichos varones

el quinto dellos fue llamado Tubal,

fijo de Jafet el terçero, del qual

vinieron después todos los españones;

quando en Babilonia por las confusiones

que de los lenguajes quedaron nasçidas,

ovieron venido en aquestas partidas

donde proçedieron diuersas naçiones (ed. ConDE, 1995b, p. 270, estrofa 255).

Apparatus: españones SA12 MN42 MN57 MU1 MM1 OC1 (xstianos [sic] españones MRE1)] españoles MN9 MN39 : espanyoles BC4.-

31 Consta perfecta e irrebatiblemente argumentada en COROMINAS-PASCUAL la imposibilidad de que la palabra lindo pudiera derivar de LIMPIDU, etimología a primera vista fácilmente asociable a la acepción que venimos comentando.

32 Real ACAdemia Española (1960- ), s.v. El gentilicio anglo no se documenta hasta 1547 (Pero Mexía). según dicho diccionario (ibid., s.v. anglo). 
La edición correcta del texto de esta estrofa en lo que nos afecta ha pasado, pese a que los testimonios manuscritos trazan un panorama libre de problemas, por peripecias merecedoras de comentario. OcHOA lee en este pasaje "vinieron despues todos los Vascones" (1844, p. 194), igual servilmente a su zaga FoulCHé-DelBosC (1915, p. $181 a)^{33}$. Es lectura sin apoyo en los mss. de la obra (vid. aparato crítico). MN63 -códice dieciochesco descriptus de OC1-, que es el ms. base de la edición de Ochoa, fol. 32r, deja en blanco el lugar de la palabra, aunque una segunda mano completa con españones. Ochoa consideró insólita la forma del gentilicio -aunque apoyada por la rima con varones-, y su perplejidad le incitó a conjeturar desafortunadamente ${ }^{34}$. Hasta SconzA (1991, p. 110), y CONDE (1995b, p. 270), el texto no recuperó su lectio genuina, españones, confirmada irremisiblemente por la rima. Es la única aparición de este gentilicio en la obra (no consta español).

Es bien sabido que españón no es ni mucho menos forma insólita del gentilicio: aparece en el Poema de Fernán González, v. 9a: "Desque los españones a Cristo conosçieron"35; aparece en el Libro de Alexandre, ms P, fol. 187r: "que eran españones de mejor cabtenençia" (WILLIS, 1935, p. 448) ${ }^{36}$; en la General Estoria: "que dizen a todos comunal mientre espannones"37; en las Siete partidas, fols. 98V, 102 v, 109r, $111 r$ (SIETE PARTIDAS, 1491); también, por último, en Juan García de Castrojeriz, Glosas al Regimiento de Príncipes de Egidio Romano: "lo que saben los españones por vso e por arte" (GARCía de CASTROJeRIZ, 1494, fol. ccxxiiv a).

Nuestro gentilicio ha hecho correr bastante tinta. Para los problemas que suscita, vid. el status quaestionis presente en LAPESA (1981, pp. 199-200), y la completa bibliografía aducida en la nota 8 de esta última, a la que apenas hay que añadir el recentísimo trabajo de MANCZAK (1996), que no deseo comentar aquí. Es de notar que la presencia de españón en Las siete edades del mundo -escritas, recordémoslo, hacia 1418modifica levemente una afirmación de Lapesa: "La forma español se sobrepuso a españón, que siempre fue minoritaria y desapareció antes de terminar el siglo XIV" (LAPESA, 1973, p. 14): tal vez el pie forzado de la rima hizo que Santa María rescatara de su memoria una forma anticuada, escudándose en las licencias que la poética del arte mayor permitía. Otro punto de interés en la historia de este gentilicio es la documentación de la forma yspañon que consta en una de las glosas presentes en la versión refundida de

33 Para las características de la edición de Ochoa y su relación con la de Foulché-Delbosc, vid. DEYERMOND (1985), p. 323 y CONDE (1991), pp. 230-31.

34 Conjetura que confundió a estudiosa tan ilustre como María Rosa Lida de Malkiel, que efectúa alguna reflexión acerca de la leyenda de Túbal como primer vasco con pie en el texto de las Siete edades según Ochoa / Foulché-Delbosc: vid. LIDA DE MALKIEL (1970), p. 45.

35 MENÉndez PIDAL (1951), p. 35; también en los vv. 26b, 140d, 161 a.

36 Sorprendentemente SAS (1976), s.v. españón, afirma que esta forma es "error por español".

37 Alfonso X, 1930. p. 55b, lín. 29 (en el aparato crítico, ms. D. p. 771b), p. 175a, lín. 17; Alfonso X (1957-1961), I. p. 114b, lín.7 para el texto que se cita. 
1460 de las Siete edades, conservada en dos mss., ML* y EM12 (s. XV): "en este tienpo florescio Trogo Ponpeo Yspañon" (ms. EM12, fol. 49v).

\section{BiBLIOGRAFÍA}

Alcover, Mn. Antoni Maria y Francesc de Borja Moll (1926-1968): Diccionari català-valencià-balear, 10 vols., Palma de Mallorca.

Alfonso X (1906): Primera Crónica General, ed. de Ramón Menéndez Pidal, Madrid, Bailly-Baillière (Nueva Biblioteca de Autores Españoles, t. V).

Alfonso X (1930): General Estoria. Primera parte, ed. de Antonio G. Solalinde, Madrid, Centro de Estudios Históricos.

Alfonso X (1957-1961): General Estoria. Segunda parte, ed. de Antonio G. Solalinde, Lloyd A. Kasten y Victor R. B. Oelschläger, 2 vols., Madrid, C.S.I.C.

Alonso, MaRTín (1986): Diccionario medieval español, Salamanca, Universidad Pontificia.

Billick, David J. y STEven N. Dworkin (1987): Lexical Studies of Medieval Spanish Texts. A Bibliography of Concordances, Glossaries, Vocabularies and Selected Word Studies, Madison; H.S.M.S.

Biluck. David J. y Steven N. Dworkin (1993): Lexical Studies of Medieval Spanish Texts. A Bibliography of Concordances, Glossaries, Vocabularies and Selected Word Studies, Madison, H.S.M.S., $2^{\mathrm{a}}$ ed.

Bogcs, Ralph, Lloyd A. Kasten, Hayward Keniston y Henry B. Richardson (1946): A Tentative Dictionary of Medieval Spanish, Chapel Hill, University of North Carolina.

BuRGOS, VICENTE DE (1494): Libro de las propiedades de las cosas, Tolosa, Enrique Mayer.

Cancionero de BaEna (1926): Cancionero de Baena. Reproduced in Facsimile from the Unique Manuscript in the Bibliothèque Nationale, Nueva York, The Hispanic Society of America.

Cancionero de Baena (1993): Cancionero de Juan Alfonso de Baena, ed. de Brian Dutton y Joaquín González Cuenca, Madrid, Visor.

Cantera Burgos, Francisco (1952): Alvar García de Santa María y su familia de conversos, Madrid, C.S.I.C.

Castro, Américo, Agustín Millares Carlo y Ángel J. Battistessa (1927): Biblia medieval romanceada, según los manuscritos escurialenses $l-j-3, l-j-8$ y $l-j-6$. $l .-$ Pentateuco, Buenos Aires, Facultad de Filosofía y Letras (Biblioteca del Instituto de Filología, I).

CeJAdOR, Julo. (1990): Vocabulario medieval castellano, Madrid, Visor.

Conde, Juan Carlos (1991): "Sobre el texto de las Siete edades del mundo de Pablo de Santa María". Actas del II Congreso Internacional de la Asociación Hispánica de Literatura Medieval (Segovia, del 5 al 9 de octubre de 1987), t. I, Alcalá de Henares, Universidad de Alcalá de Henares, pp. 229-43.

Conde, Juan Carlos (1995a): Reseña de SConza (1991), RPh, 48/3, pp. 322-331.

Conde, Juan Carlos (1995b): "Las siete edades del mundo» de Pablo de Santa María. Estudio y edición crítica, 2 vols., Madrid, Ediciones de la Universidad Autónoma de Madrid (Tesis doctoral, Universidad Autónoma de Madrid, 1994), microfichas. 
Conde, Juan Carlos (en prensa): Pablo de Santa María, «Las siete edades del mundo». Edición crítica y estudio, Salamanca, Universidad de Salamanca (Colección Textos recuperados).

Conde, Juan Carlos y Victor Infantes (1990): "Prólogo" a Cejador (1990).

Connoly, Jane E. (1987): Translation and Poetization in the Quaderna Vía. Study and Edition of the "Libro de miseria d'omne», Madison, H.S.M.S.

Corominas, JoAn y JoSÉ ANTONIO PASCUAL (1980-1991): Diccionario crítico-etimológico castellano e hispánico, 6 vols., Madrid, Gredos.

COROMINES, JOAN (1980-1991): Diccionari etimològic $i$ complementari de la llengua catalana, amb la col'laboració de Joseph Gulsoy i Max Cahner, 9 vols., Barcelona. Curial Edicions Catalanes - "La Caixa".

CovarRuBias, SebAStiAn de (1943): Tesoro de la lengua castellana o española [1611]. ed. de Martín de Riquer, Barcelona, Horta.

Crónica de Álvaro de luna (1940): Crónica de don Álvaro de Luna, condestable de Castilla, maestre de Santiago [c1475], ed. de Juan de Mata Carriazo, Madrid, Espasa-Calpe.

Deyermond, Alan (1985): "Historia universal e ideología nacional en Pablo de Santa María". Homenaje a Álvaro Galmés, t. II, Madrid-Oviedo, Gredos-Universidad de Oviedo, pp. 313-324.

Du CANGE (1840-1850): Glossarium mediae et infimae latinitatis, 7 vols., París, Firmin Didot.

DutTon, Brian (1990-1991): El Cancionero del siglo XV (c.1360-1520), 7 vols., Salamanca, Biblioteca Española del Siglo XV.

DWORKIn, SteVEn (1994): "Progress in Medieval Spanish Lexicography", RPh, 47/4, pp. 406-425.

FernÁNDEZ de SantAella, Rodrigo (1499): Vocabularium ecclesiasticum, Sevilla, Juan Pegnitzer, Magno Herbst y Tomás Glockner.

Foulché-Delbosc, RaYmond (1915): Cancionero castellano del siglo XV, t. II, Madrid, Bailly-Baillière (Nueva Biblioteca de Autores Españoles, t. XXII).

GAFFIOT, Felix (1934): Dictionnaire illustré Latin-Français, París, Hachette.

García de Castrojeriz, Juan (1494): Glosas al Regimiento de Príncipes de Egidio Romano, Sevilla. Ungut y Polono.

GODEFROY. FRÉDÉRIC (1880-1902). Dictionnaire de l'ancienne Langue française et de tous ses dialectes du IXe au XVe siècle, 10 vols., París, Vieweg - É. Bouillon.

González RolÁn, Tomás y Felisa del BarRio Vega (1989): "Juan de Mena, Sumas de la Yliada de Omero", Revista de Filología Románica, 6, pp. 147-228.

Hauptmann, O. H. (1953): Escorial Bible I.j.4. Volume I. The Pentateuch, Filadelfia, University of Pennsylvania Press for Grinnell College Press.

Jiménez de URRea, Pedro Manuel (1878): Cancionero, Zaragoza, Imprenta del Hospicio Provincial. Krieger, Judith Gale (1988): Pablo de Santa María: His Epoch, Life, and Hebrew and Spanish Literary Production, Michigan, U.M.I. (Ph. D., University of California Los Angeles, 1988).

LAPESA, RAFAEL (1973): "Sobre el origen de la palabra 'español"', en Américo Castro, Sobre el nombre y el quién de los españoles, Madrid, Taurus, pp. 11-16.

LAPESA, RAFAEL (1981): Historia de la lengua española, Madrid, Gredos, $9^{a}$ ed.

LIDA DE MALKIEL, MARIA RoSA (1970): “Túbal, primer poblador de España”, Ábaco, 3, pp. 9-48.

LIRA, NICOLÁS DE (1502): Postilla super totam Bibliam, en Biblie iam pridem renouate pars prima: complectens pentateuchum: vna cum glosa ordinaria: et litterali moralisque expositione $\mathrm{Ni}$ colai de lyra: necnon additionibus Burgensis: ac replicis Thoringi: novisque distinctionibus et marginalibus summarijsque annotationibus, 6 vols.. Basilea, Johannes Froben y Johannes Petri.

LiTTRÉ, É. (1863-1869): Dictionnaire de la Langue française, 2 vols. en 4 tomos. Paris, Hachette. MANCZAK, Witold (1996): "Origine de l'espagnol español", RPh, 49/3, pp. 277-283. 
MANuel, Juan (1982): Obras completas, ed. de José Manuel Blecua, t. I, Madrid, Gredos.

MARTÍNEZ-LÓPEZ, RAmón (1963): General Estoria. Versión gallega del siglo XIV, ms. O.l.1 del Escorial, Oviedo, Universidad de Oviedo.

Menéndez Pidal, Ramón (1951): Reliquias de la poesía épica española. Madrid, Espasa Calpe.

MonTORO, ANTÓN DE (1900): Cancionero, ed. de Emilio Cotarelo y Mori, Madrid, Impa de José Perales.

Montoro, Antón de (1984): Cancionero, ed. de Francisco Cantera Burgos y Carlos Carrete Parrondo, Madrid, Editora Nacional.

Montoro, AnTón DE (1990a): Cancionero, ed. de Marcella Ciceri, introducción y notas de Julio Rodríguez-Puértolas, Salamanca, Biblioteca Española del Siglo XV.

Montoro, Antón de (1990b): Poesía completa, ed. de Marithelma Costa, Cleveland, Cleveland State University.

NebRIJA, Elo Antonio (1492): Dictionarium latino-hispanicum, Salamanca.

NEBRIJA, Elo ANTONIO (1495): Dictionarium hispano-latinum, Salamanca.

NiERMEYER, J. F. (1984): Mediae latinitatis lexicon minus, Leiden, Brill.

OCHOA. EUGENIO DE (1844): Rimas inéditas de don Iñigo López de Mendoza, Marqués de Santillana, de Fernán Pérez de Guzmán, Señor de Batres, y de otros poetas del siglo XV, París, ed. del autor, impr. Fain y Thunot.

OELSCHLÄGER, VICTOR R. B. (1940): A Medieval Spanish Word-List: A Preliminary Dated Vocabulary of First Appearances up to Berceo, Madison. University of Wisconsin Press.

O'Kane, Eleanor S. (1950): "On the names of the Refrán", HR, 18, pp. 1-14.

OXford Latin DictionaRy (1986): Oxford Latin Dictionary, Oxford, The Clarendon Press.

PALENCIA, AlfoNSO DE (1490): Universal vocabulario en latín y en romance, Sevilla, Pablo de Colonia [cuatro compañeros alemanes].

PaZ y Melia, A. y Julián PAZ (1920-1922): Biblia (Antiguo Testamento) traducida del hebreo al castellano por Rabí Mosé Arragel de Guadalfajara (1422-1433?) y publicada por el Duque de Berwick y de Alba, 2 vols., Madrid, Imprenta Artística.

Quevedo, Francisco de (1932): Obras, I. Prosa, ed. de Luis Astrana Marín, Madrid, Aguilar.

ReAl ACADEmia Española (1726-1739): [Diccionario de Autoridades] Diccionario de la lengua castellana, 6 vols., Madrid, Real Academia Española.

ReAl ACADEMIA ESPAÑola (1780): Diccionario de la lengua castellana (reducido a un tomo para su más fácil uso), Madrid. Real Academia Española.

[Real] ACADEmia Española (1933-1936): Diccionario histórico de la lengua española, 2 vols., Madrid, Academia Española.

Real ACAdemia Española (1960- ): Diccionario histórico de la lengua española, 2 vols. (en curso de publicación), Madrid, Real Academia Española.

Real ACademia Española (1992): Diccionario de la lengua española, Madrid, Espasa Calpe, $21^{\mathrm{a}} \mathrm{ed}$. Rodriguez de Almela, Diego (1487): Valerio de las historias escolasticas y de España, Murcia, Lope de Roca.

SaAvedRa Fajardo, Diego (1973): República literaria [c1613], ed. de Vicente García de Diego, Madrid, Espasa-Calpe (Clásicos Castellanos, 46).

Santa María, PABlo de (1502): Additiones ad postillas Nicolai de Lyra, en Biblie iam pridem renouate pars prima: complectens pentateuchum: vna cum glosa ordinaria: et litterali moralisque expositione Nicolai de lyra: necnon additionibus Burgensis: ac replicis Thoringi: novisque distinctionibus et marginalibus summarijsque annotationibus, 6 vols., Basilea, Johannes Froben y Johannes Petri.

SAS, L. F. (1976): Vocabulario del "Libro de Alexandre", Madrid, RAE (Anejo XXXIV del BRAE). 
SCHMidT, WalTeR (1951): Der Wortschatz des "Cancionero de Baena», Berna, A. Francke.

SconZA, M. JeAn (1991): History and Literature in Fifteenth Century Spain: An Edition and Study of Pablo de Santa María's "Siete edades del mundo". Madison, H.S.M.S.

SerRano, Luciano (1942): Los conversos D. Pablo de Santa María y D. Alfonso de Cartagena. Obispos de Burgos, gobernantes, diplomáticos y escritores, Madrid, C.S.I.C.

SerRano y Sanz, Manuel (1902): "Noticias bibliográficas de Fernando de Rojas, autor de $\mathrm{La} \mathrm{Ce}$ lestina, y del impresor Juan de Lucena", RABM, $3^{\mathrm{a}}$ época, 6. pp. 245-299.

Siete PARTIDAS (1491): Las siete partidas de Alfonso X el Sabio. Sevilla, Meinardo Ungut y Estanislao Polono.

SmitH, C. C. (1959): "Los cultismos literarios del Renacimiento. Pequeña adición al Diccionario Crítico Etimológico de Corominas", BHi, 61, pp. 236-272.

SPITZER, Leo (1955): "Latin médieval brocard(ic)a > français brocard", MLN, 70, pp. 501-506.

TERREROS Y PANDO, ESTEBAN (1786-93): Diccionario castellano con las voces de ciencias y artes y sus correspondientes en las tres lenguas francesa, latina e italiana, 4 vols., Madrid.

TeSAURO, Pompilio (1985): "El cultismo léxico en el Libro de miseria de omne", BBMP, 61, pp. 514.

Thesaurus Linguae Latinae (1900- ), Thesaurus linguae latinae, 10 vols. (en curso de publicación), Leipzig. Teubner.

Toledo, AlfoNSO DE (1992): Invencionario [c1467], ed. de Philip O. Gericke, Madison, H.S.M.S.

TorRes VillarRoel, Diego (1794): Sueños morales, t. III, Madrid, Viuda de Ibarra.

TRÉSOR DE LA LANGUE FRANÇAISE (1971-1994): Trésor de la Langue française. Dictionnaire de la Langue du XIXe et du XXe siècle (1789-1960), 16 vols., Paris, CNRS - Gallimard.

Ufano, Diego (1613): Tratado de la artillería y uso della, Bruselas, Juan Momarte.

Willis, Raymond S. (1935): El libro de Alexandre. Texts of the Paris and the Madrid Manuscripts with an Introduction, Princeton. Princeton University Press (Elliott Monographs, 32). 